\title{
Identification of ACOT13 and PTGER2 as novel candidate genes of autosomal dominant polycystic kidney disease through whole exome sequencing
}

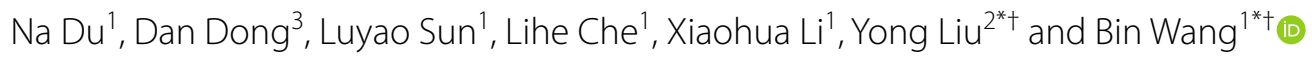

\begin{abstract}
Background: Autosomal dominant polycystic kidney disease (ADPKD) is the most common monogenic kidney disorder. Half of the patients would slowly progress to end-stage renal disease. However, the potential target for ADPKD treatment is still lacking.
\end{abstract}

Methods: Four ADPKD patients and two healthy family members were included in this study. The peripheral blood samples were obtained and tested by the whole exome sequencing (WES). The autosomal mutations in ADPKD patients were retained as candidate sites. The Gene Ontology (GO), Kyoto Encyclopedia of Genes and Genomes (KEGG) enrichment, and protein-protein interaction network (PPI) analyses were performed by clusterProfiler R package. A dataset containing 18 ADPKD patients and three normal samples were downloaded from the Gene Expression Omnibus (GEO) database and analyzed using the limma R package.

Results: A total of six mutant genes were identified based on the dominant genetic pattern and most of them had not been reported to be associated with ADPKD. Furthermore, 19 harmful genes were selected according to the harmfulness of mutation. GO and KEGG enrichment analyses showed that the processes of single-organism cellular process, response to stimulus, plasma membrane, cell periphery, and anion binding as well as cyclic adenosine monophosphate (CAMP) signaling pathway and pathways in cancer were significantly enriched. Through integrating PPI and gene expression analyses, acyl-CoA thioesterase 13 (ACOT13), which has not been reported to be related to ADPKD, and prostaglandin E receptor 2 (PTGER2) were identified as potential genes associated with ADPKD.

Conclusions: Through combination of WES, gene expression, and PPI network analyses, we identified ACOT13 and PTGER2 as potential ADPKD-related genes.

Keywords: Whole exome sequencing, Gene mutations, Polycystic kidney disease, ACOT13, PTGER2

*Correspondence: liuyong0228@jlu.edu.cn; wangbinlucky2018@jlu.edu.cn

${ }^{+}$Yong Liu and Bin Wang contributed equally to this work

${ }^{1}$ Infectious Diseases Department, The First Hospital of Jilin University, No.1 Xinmin Street, Changchun 130021, Jilin, China

${ }^{2}$ Genetic Diagnosis Center, The First Hospital of Jilin University, No.1 Xinmin Street, Changchun 130021, Jilin, China

Full list of author information is available at the end of the article

\section{Introduction}

Polycystic kidney disease (PKD) is a group of monogenic disorders, and is the common cause of end-stage renal disease. Most adult patients are affected by the autosomal dominant form (ADPKD), while the autosomal recessive polycystic kidney disease (ARPKD) is a rarer form that usually presents perinatally or in early childhood [1]. Mutations in PKD1 and PKD2, which encode polycystin original author(s) and the source, provide a link to the Creative Commons licence, and indicate if changes were made. The images or other third party material in this article are included in the article's Creative Commons licence, unless indicated otherwise in a credit line to the material. If material is not included in the article's Creative Commons licence and your intended use is not permitted by statutory regulation or exceeds the permitted use, you will need to obtain permission directly from the copyright holder. To view a copy of this licence, visit http://creativecommons.org/licenses/by/4.0/. The Creative Commons Public Domain Dedication waiver (http://creativeco mmons.org/publicdomain/zero/1.0/) applies to the data made available in this article, unless otherwise stated in a credit line to the data. 
1 and 2 ( $\mathrm{PC} 1$ and $\mathrm{PC} 2$ ) proteins, are the most common causes of ADPKD. PC2, a cation channel, is a member of the transient receptor potential (TRP) family of ion channels [2]. It was reported that defects in PKD2 trigger changes in mitochondrial energy metabolism [3]. the roles of PC1 and PC1PC2 complex are poorly understood [4]. Although PKD is inherited monogenically, it is heterogeneous in phenotype, gene, and allele [1], and 7\% of ADPKD families are genetically unresolved [5]. Moreover, the molecular mechanisms underlying the renal dysfunction resulted from mutations in PKD genes and the physiological functions of polycystin proteins are also still unclear [6].

The targeted resequencing by pooling long-range polymerase chain reaction (LR-PCR) amplicons has been used in the identification of mutations in PKD. Despite its high sensitivity, specificity, and accuracy, the challenge in data interpretation limits the development of potential targets in PKD therapy [7]. In recent years, the whole genome sequencing (WGS) and whole exome sequencing (WES) have been increasingly applied to the diagnostic evaluation of patients with suspected genetic disorders, including detection of rare genetic events and new mutations contributing to disease [8]. Mallawaarachchi AC et al. reported that WGS could overcome the pseudogene homology and provide an efficient strategy for ADPKD diagnosis [9]. Moreover, the results of Daniela AB et al. confirmed that WES could detect the causative mutation in $2 / 3$ of the affected individuals with chronic kidney disease including ARPKD, which would allow the identification of potential genes associated with kidney disease [10].

Here, we performed the WES using the blood samples of four ADPKD patients and two healthy family members to analyze their genes variation. In addition, a gene expression dataset containing 18 ADPKD patients and three normal samples were obtained from the Gene Expression Omnibus (GEO) database. Through integrated analyses of gene mutation, gene expression, gene function enrichment, and protein-protein interaction (PPI), we identified two genes (ACOT13 and PTGER2) which were potentially associated with the pathogenesis of ADPKD.

\section{Materials and methods \\ Clinical information}

This study was approved by the local ethics committee (approval number: 2019-307). An ADPKD patient treated in our hospital and five members of this family were included in this study. This patient had a history of polycystic kidney disease, polycystic liver disease, and kidney stones for 13 years (Additional file 1: Table S1). The pedigree of this family is shown in Fig. 1A. The N_2 was this proband. The N_4, N_5, and N_6 were all ADPKD patients (black), whereas $\mathrm{N} \_3$ and $\mathrm{N} \_1$ were healthy people (white). In total, there were four ADPKD patients and two healthy controls in our study. The clinical symptoms of this proband included fever, back pain, and hematuria. The computed tomography (CT) examination of $\mathrm{N} \_2$ revealed multiple cysts in the liver and bilateral polycystic kidney. Some lesions were complex cysts, with changes in the right perirenal exudation that had blurred outlines and increased density (Fig. 1B).

\section{Whole exome sequencing}

The genome DNA was extracted from peripheral blood samples using a DNA extraction kit (Tiangen Biotech, Beijing, China), and the exomes were captured using the Agilent SureSelect Human All Exon V6 kit (Agilent Technologies, Santa Clara, CA) according to the instructions of the kits. Whole-exome sequencing was performed using the Illumina Novaseq6000 instruments with
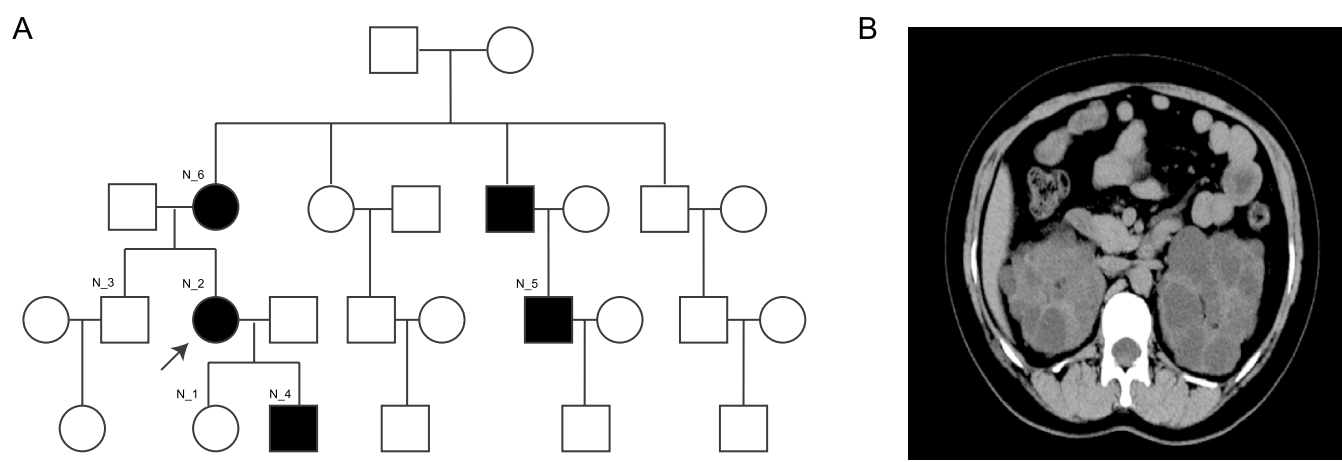

Fig. 1 Family status of polycystic kidney patients. A Pedigree plot of N_2 with polycystic kidney disease. B Abdominal computed tomography (CT) of $N \_$2. In this figure, the polycystic kidney disease cases included the patient's mother N_6, son N_4, and cousin N_5. The normal controls without disease consisted of the patient's younger brother N_3 and daughter N_1 
paired-end 150-bp sequencing reads. Raw sequencing reads were preprocessed to remove the low-quality bases and reads using fastp [11], an ultra-fast all-in-one FASTQ preprocessor, and the default parameters were adopted. The sequence reads were aligned to the human genome (Build-UCSC hg19) using the BWA (Burrow-Wheeler Aligner, http://bio-bwa.sourceforge.net/) software. Then, single nucleotide polymorphism (SNP) and Insertion/deletion (Indel) were identified with the SAMtools software (http://samtools.sourceforge.net/). Using the ANNOVAR software (http://annovar.openbioinformat ics.org/en/latest/user-guide/download/), functional annotation was performed for the identified SNP and Indel to investigate their genomic locations and variation information (Additional file 2: Table S2).

\section{Screening of candidate SNP/Indel for ADPKD}

We first removed mutations with frequencies higher than $1 \%$ in at least one of the four databases $\left(1000 \mathrm{~g} \_\right.$all, esp6500si_all, gnomAD_ALL, and gnomAD_EAS). Then, mutations in exonic or splicing (10 bp upstream and downstream of the exon) positions were retained. Small fragments $(<10 \mathrm{bp})$ non-frameshifting Indel mutations in the repeat region were also removed. In addition, mutations that met one of the following conditions were retained: (a) The sites that were considered as harmful by at least half of the four softwares SIFT [12], Polyphen [13], MutationTaster [14], and CADD [15] basing on the scores; (b) mutations that were predicted to affect the splicing by dbscSNV [16]. Then, the genetic mutations that were classified into Pathogenic and Likely Pathogenic ones according to the Criteria and guidelines for grading clinical significance of single gene mutations of American College of Medical Genetics and Genomics (ACMG, https://www.acmg.net/) were selected as candidate sites. For the screening of dominant genetic pattern, on the basis of mutation site filtering, the sites showing autosomal mutations in ADPKD patients, which, however, could not be detected in normal controls were retained as candidate sites.

\section{Functional enrichment and PPI analyses}

The Gene Ontology (GO; http://geneontology.org) (including Biological Process, Molecular Function, and Cellular Component) and Kyoto Encyclopedia of Genes and Genomes (KEGG; https://www.genome.jp/kegg/) enrichment analyses were conducted to analyze the function of candidate SNP/Indel-related genes using the clusterProfiler package in R [17]. In addition, PPI network analysis of candidate SNP/Indel-related genes was carried out using the STRING database (https://string-db. org/cgi/input.pl).

\section{Differential expression analysis}

The mRNA expression profile data of GSE7869 [18] was downloaded from the GEO database (https://ncbi.nlm. nih.gov/geo), which was detected based on Affymetrix Human Genome U133 Plus 2.0 Array. The GSE7869 dataset contained 18 ADPKD samples and three normal samples. The mRNA expression profile data was analyzed using the limma function package in $\mathrm{R}$ [19]. Differentially expressed genes (DEGs) were selected using the thresholds of absolute value of differential expression $(|\log 2 \mathrm{FC}|)>0.5$ and $P$ value $<0.05$.

\section{Statistical analysis}

Statistical analyses were performed using $\mathrm{R}$ software v3.5.2. $P$ value $<0.05$ was considered statistically significant in all statistical analyses.

\section{Results}

\section{Mutational landscape}

The total number of SNPs in the six samples was concentrated between 100,000 and 150,000, and they were mainly located in the intron region, exon region, and intergenic region (Fig. 2A). The total number of Indels in the six samples was concentrated between 15,000 and 20,000, and these Indels mainly distributed in the intron and intergenic region (Fig. 2B). We next explored the landscape of mutations that were located in the coding region. Consequently, the SNPs of six samples in the coding region mainly included anonymous, missense, and stoploss mutations, whose cumulative number was nearly 21,000 (Fig. 2C). The Indels of six samples in the coding region mainly consisted of nonframeshift_deletion and nonframeshift_insertion (Fig. 2D).

\section{Potential mutations and genes for ADPKD}

Six mutant genes, including AGRN, ACOT13, ADCY4, HEATR5A, PTGER2, and ADAM21, were screened using the dominant genetic pattern. They were heterozygously mutated in ADPKD samples but not mutated in normal samples. Most of these genes have not been reported to be related to the occurrence of ADPKD. Meanwhile, 19 genes were also selected according to the harmfulness of mutation, including $M U T Y H$, USH $2 A, H B S 1 L$, GLI3, SBDS, SND1, ABCA2, RPS6KA4, FLVCR1, ATIC, SCN11A, ATP6V1A, GLRA1, PRMT8, PKD1, INSL3, SUPT5H, NCF4, and GPR143. To study the relationship between those gene mutations and ADPKD, we first analyzed the effects of gene mutations on proteins. Consequently, all those genes had at least one mutation that 
A

$\begin{array}{lll}\text { exonic } & \text { UTR3 } & \text { intergenic } \\ \text { intronic } & \text { UTR5 } & \text { downstream } \\ \text { splicing }\end{array}$

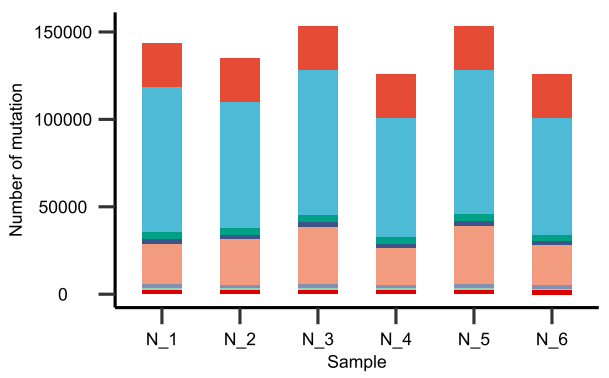

C

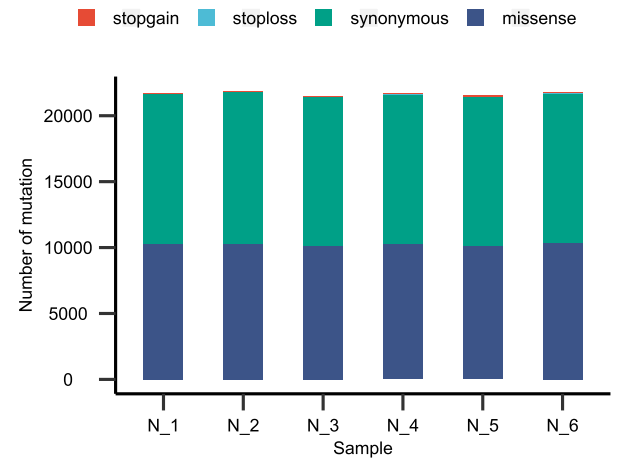

B

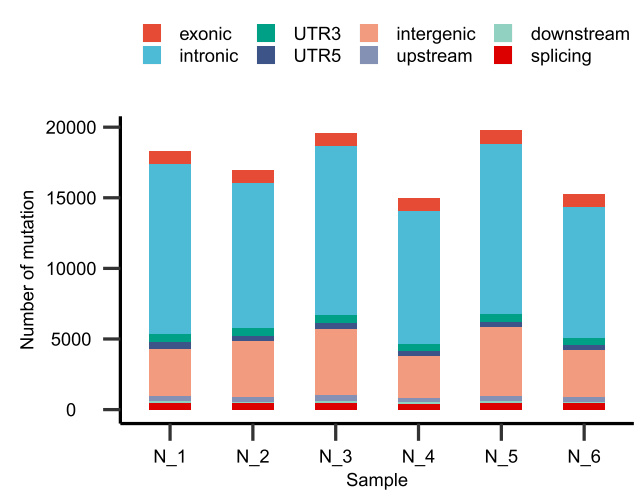

D

$\begin{array}{lll}\text { stoploss } & \text { nonframeshift_deletion } \\ \text { nonframeshift_insertion } & \begin{array}{l}\text { frameshift_deletion } \\ \text { frameshift_insertion }\end{array}\end{array}$

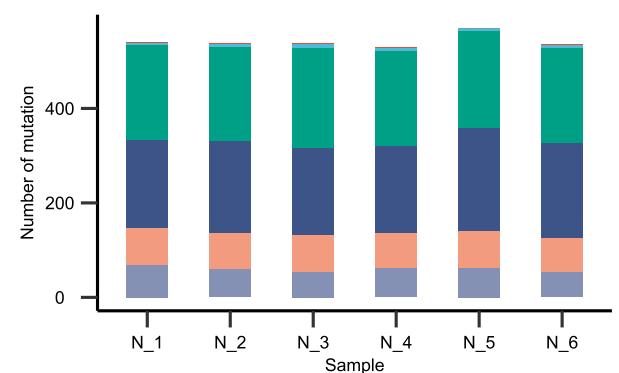

Fig. 2 Distribution of mutations. Distribution across genomic features of all single-nucleotide variations (SNVs) (A) and Indels (B). Distribution across genomic features of SNVs (C) and Indels (D) located in coding region

could affect the coding of protein, indicating the potential roles of those mutations (Table 1).

\section{Significantly enriched KEGG pathways and GO terms of potential ADPKD-related genes}

The results of GO and KEGG enrichment analyses of the 25 potential genes associated with ADPKD are shown in Fig. 3A (Biological Process), Fig. 3B (Cellular Component), Fig. 3C (Molecular Function), and Fig. 3D (KEGG). GO analysis showed that these 25 genes were significantly enriched in the biological processes (BP) of singleorganism cellular process and response to stimulus, cell components (CC) of plasma membrane and cell periphery, and molecular function (MF) of anion binding. In addition, the KEGG pathway analysis revealed that these 25 genes were mainly enriched in cyclic adenosine monophosphate (cAMP) signaling pathway and pathways in cancer.

\section{ACOT13 and PTGER2 might be candidate genes associated with ADPKD}

The PPI network analysis was performed to explore the association among the 25 potential ADPKD-related genes. As shown in Fig. 3E, most of those genes were independent in the network. ACOT13 had direct interaction with both SBDS and ATIC; PTGER2, ADCY4, and INSL3 were predicted to interact with each other (Fig. 3E). What's more, ACOT13, PTGER2, and ADCY4 were genes that only mutated in ADPKD patients. , based on the expression data downloaded from the GEO database, we compared the expression levels of ACOT13, PTGER2, and ADCY4 between the ADPKD patients and the normal controls. Compared with the normal controls, the expression level of ACOT13 was significantly lower in ADPKD patients (Fig. 4A), while PTGER2 presented a higher expression level in ADPKD patients (Fig. 4B). $A D C Y 4$ did not exhibit significant expression difference between ADPKD patients and normal samples (Fig. 4C). Combining the information, we speculated that ACOT13 and PTGER2 might be candidate genes associated with ADPKD.

\section{Discussion}

ADPKD is caused by mutation in one of two genes-78\% of cases are caused by mutation in PKD1 on chromosome 16 and $15 \%$ of cases are caused by mutation in 
Table 1 The protein changes of 25 genes

\begin{tabular}{|c|c|c|c|}
\hline Gene name & Region & AA change & Screening method \\
\hline AGRN & Exonic & NM_198576: exon10: c.G1855A: p.V619M & Dominant inheritance pattern \\
\hline \multirow[t]{2}{*}{ ACOT13 } & \multirow[t]{2}{*}{ Exonic } & NM_018473: exon3: c.G295T: p.D99Y & \multirow[t]{2}{*}{ Dominant inheritance pattern } \\
\hline & & NM_001160094: exon4: c.G226T: p. D76Y & \\
\hline ADCY4 & Splicing & & Dominant inheritance pattern \\
\hline HEATR5A & Exonic & NM_015473: exon17: c.C2449G: p.H817D & Dominant inheritance pattern \\
\hline PTGER2 & Exonic & NM_000956: exon1: c.G401A: p. R134H & Dominant inheritance pattern \\
\hline ADAM21 & Exonic & NM_003813: exon2: c.A945G: p. I315M & Dominant inheritance pattern \\
\hline \multirow[t]{2}{*}{$A B C A 2$} & \multirow[t]{2}{*}{ Exonic } & NM_001606: exon9: c.C1045T: p.Q349X & \multirow[t]{2}{*}{ Harmful screening } \\
\hline & & NM_212533: exon9: c.C1135T: p. Q379X & \\
\hline ATIC & Exonic & NM_004044: exon15: c.A1568T: p. E523V & Harmful screening \\
\hline ATP6V1A & Exonic & NM_001690: exon4: c.415dupA: p.C138fs & Harmful screening \\
\hline FLVCR1 & Exonic & NM_014053: exon1: c.A551C: p. N184T & Harmful screening \\
\hline GLI3 & Splicing & & Harmful screening \\
\hline \multirow[t]{3}{*}{ GLRA1 } & \multirow[t]{3}{*}{ Exonic } & NM_001292000: exon8:c.C1075T: p.R359C & \multirow[t]{3}{*}{ Harmful screening } \\
\hline & & NM_000171: exon9:c.C1324T: p. R442C & \\
\hline & & NM_001146040: exon9:c.C1348T: p. R450C & \\
\hline GPR143 & Exonic & NM_000273: exon1: c.134_179del: p. L45fs & Harmful screening \\
\hline \multirow[t]{2}{*}{ HBS1L } & \multirow[t]{2}{*}{ Exonic } & NM_001145158: exon15: c. A1762T: p.K588X & \multirow[t]{2}{*}{ Harmful screening } \\
\hline & & NM_006620: exon16: c.A1888T: p. K630X & \\
\hline \multirow[t]{2}{*}{ INSL3 } & \multirow[t]{2}{*}{ Exonic } & NM_001265587: exon1: c.148dupC: p. R50fs & \multirow[t]{2}{*}{ Harmful screening } \\
\hline & & NM_005543: exon1: c.148dupC: p. R50fs & \\
\hline MUTYH & Splicing & & Harmful screening \\
\hline \multirow[t]{2}{*}{ NCF4 } & \multirow[t]{2}{*}{ Exonic } & NM_000631: exon3:c.C178T: p.R60C & \multirow[t]{2}{*}{ Harmful screening } \\
\hline & & NM_013416: exon3:c.C178T: p. R60C & \\
\hline \multirow[t]{2}{*}{ PKD1 } & \multirow[t]{2}{*}{ Exonic } & NM_000296: exon39:c.C11254T: p.R3752W & \multirow[t]{2}{*}{ Harmful screening } \\
\hline & & NM_001009944: exon39:c.C11257T: p. R3753W & \\
\hline PRMT8 & Exonic & $\begin{array}{l}\text { NM_001256536: exon2: c.54_66del: p. N18fs NM_019854: } \\
\text { exon2: c.81_93del: p. N27fs }\end{array}$ & Harmful screening \\
\hline \multirow[t]{4}{*}{ RPS6KA4 } & \multirow[t]{4}{*}{ Exonic } & NM_001006944: exon7: c.G755A: p.R252Q & \multirow[t]{4}{*}{ Harmful screening } \\
\hline & & NM_001300802: exon7: c.G755A: p.R252Q & \\
\hline & & NM_001318361: exon7: c.G566A: p. R189Q & \\
\hline & & NM_003942: exon7: c.G755A: p. R252Q & \\
\hline SBDS & Splicing & & Harmful screening \\
\hline SCN11A & Exonic & $\begin{array}{l}\text { NM_014139: exon14: c.G2386A: p.V796M } \\
\text { NM_001349253: exon 18: c.G2386A: p.V796M }\end{array}$ & Harmful screening \\
\hline SND1 & Exonic & NM_014390: exon7:c.C694T: p. R232X & Harmful screening \\
\hline SUPT5H & Splicing & & Harmful screening \\
\hline USH2A & Splicing & & Harmful screening \\
\hline
\end{tabular}

PKD2 on chromosome 4 [20]. The cystic kidney diseases have also been termed ciliopathies. The PC1 and PC2 proteins, encoded by PKD1 and PKD2, are both located on the primary cilia and act as flow sensors in the kidney [21]. In this study, the harmful mutation in $P K D 1$, as well as other 18 known harmful genes, were detected in the samples of ADPKD patients. Moreover, six mutants, including $A G R N, A C O T 13, A D C Y 4$, HEATR5A, PTGER2, and ADAM21, were screened using the dominant genetic pattern and most of them had not been previously recognized as ADPKD-related pathogenic genes.

The pathogenic proteins in ADPKD are mainly responsible for transmitting information from the external environment to the cells [22]. We analyzed the potential functions of the 25 identified genes by GO and KEGG enrichment analyses. The results showed that the BPs of single-organism cellular process, response to stimulus, as well as CCs of plasma membrane and cell periphery were significantly enriched. Besides, ADPKD cells can shift 

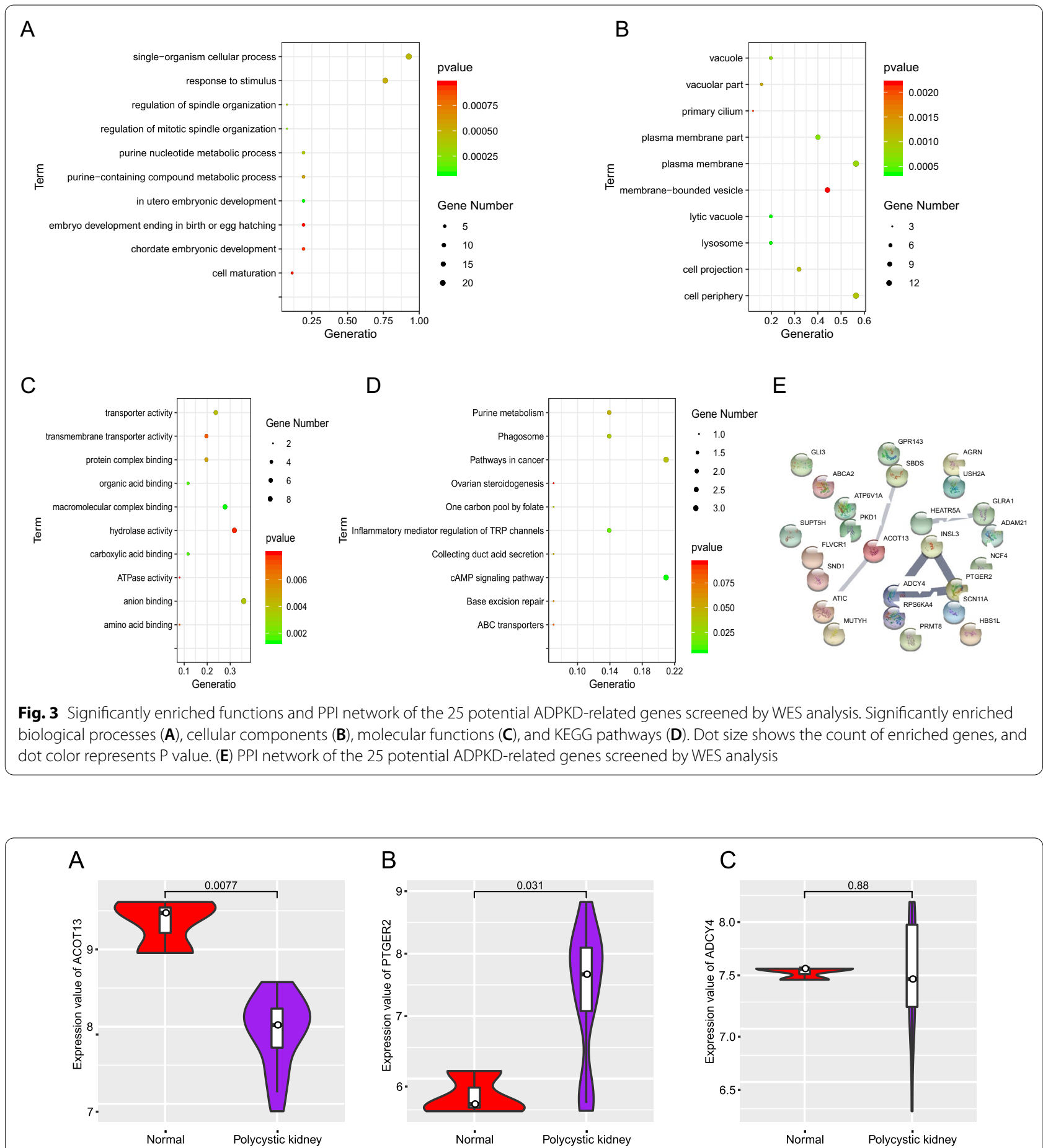

Fig. 4 Boxplots illustrating the mRNA expression levels of ACOT13 (A), PTGER2 (B), and ADCY4 (C) between ADPKD patients and normal controls

their mode of energy production from oxidative phosphorylation to other pathways, and these alterations in cell metabolism have emerged as a hallmark of ADPKD [6]. The alterations in modulation of energy production and utilization in ADPKD are dependent on several inner cellular signaling pathways, such as AMP-activated protein kinase (AMPK), calcium signaling at mitochondriaassociated membranes, mammalian target of rapamycin complex 1 (mTORC1), cAMP, and cystic fibrosis transmembrane conductance regulator (CFTR)-mediated ion 
transport [23, 24]. Here, the cAMP signaling pathway was identified as the significantly enriched one in these ADPKD samples. These results support the reliability of the mutations we screened. Meanwhile, despite functional information was partly revealed by enrichment analysis, more details of the 25 identified genes deserved further exploration in ADPKD in the future.

The PPI and differential expression analyses indicated that compared with normal people, ACOT13 and PTGER2 were mutated and differentially expressed in ADPKD patients, and might be the potential genes associated with ADPKD. ACOT13 protein is a member of acyl-CoA thioesterases (Acots) enzymes, which catalyze the reaction of hydrolysis of fatty acyl-CoA molecules into free fatty acids plus CoASH. ACOT13 is enriched in oxidative tissues, and is associated with mitochondria [25]. Lin et al. reported that PC1 affected mitochondria morphology and function, which might play a key role in regulating mitochondrial function and cellular metabolism [26]. To our knowledge, there have not been reports on the relationship between ACOT13 and ADPKD. The expression of PTGER2 affects the biologic behavior of various types of malignant tumors [27-29], which should be related to the enrichment of pathways in cancer in KEGG analysis. Otherwise, the role of prostaglandin E (2) (PGE2) in the cystogenesis in genetically nonorthologous models of ADPKD has already been studied. Liu et al. found that PGE2 could activate the aberrant signaling pathways in $\mathrm{PC}-1$-deficient epithelia, and mediate the proliferation and chloride secretion in ADPKD cystic renal epithelia [30]. Elberg et al. have indicated the role of PTGER2 in mediation of PGE2 effect on inducing formation of cyst through combined biochemical, pharmacological, and functional analyses in ADPKD [31]. This further confirms the reliability of our approach on pathogenic genes screening in ADPKD, which may be applicable in other diseases. It also indirectly supports the reliability of ACOT13 as a potential ADPKD-related gene. However, the underlying biological function of ACOT13 in ADPKD still warrants further studies.

\section{Conclusions}

In this study, we identified two potential ADPKD-related genes, including ACOT13 and PTGER2, by analyzing the WES results of four ADPKD patients and two healthy family members combining with the gene expression data from GEO database. Our results may be helpful for further studies in the underlying pathologic causes of ADPKD. However, due to the small number of patients in our study, there remains some uncertainty about the potential role of ACOT13 and PTGER2, which still warrants further studies.

\section{Supplementary Information}

The online version contains supplementary material available at https://doi. org/10.1186/s40001-021-00613-8.

Additional file 1: Table S1. Clinical details of ADPKD patients.

Additional file 2: Table S2. Raw molecular data.

Acknowledgements

Not applicable.

Authors' contributions

Conceptualization, ND and DD; data curation and formal analysis, LS, LC and $\mathrm{XL}$; writing - original draft preparation, ND and $Y L$; writing - review and editing, YL and BW. All authors have read and agreed to the published version of the manuscript. All authors read and approved the final manuscript.

Funding

This research received no external funding.

Availability of data and materials

All data generated and analysed during this study are included in this published article and its additional information files.

\section{Declarations}

\section{Ethics approval and consent to participate}

This study was approved by The First Hospital of Jilin University Committee (approval number: 2019-307).

\section{Consent for publication}

All study subjects signed written informed consent.

\section{Competing interests}

The authors declare that they have no competing interests.

\section{Author details}

${ }^{1}$ Infectious Diseases Department, The First Hospital of Jilin University, No.1 Xinmin Street, Changchun 130021, Jilin, China. ${ }^{2}$ Genetic Diagnosis Center, The First Hospital of Jilin University, No.1 Xinmin Street, Changchun 130021, Jilin, China. ${ }^{3}$ Department of Obstetrics and Gynecology, The First Hospital of Jilin University, No.1 Xinmin Street, Changchun 130021, Jilin, China.

Received: 13 July 2021 Accepted: 18 November 2021

Published online: 09 December 2021

\section{References}

1. Bergmann C, Guay-Woodford LM, Harris PC, Horie S, Peters DJM, Torres VE. Polycystic kidney disease. Nat Rev Dis Primers. 2018;4(1):50. https://doi. org/10.1038/s41572-018-0047-y.

2. Grieben M, Pike AC, Shintre CA, Venturi E, El-Ajouz S, Tessitore A, Shrestha L, Mukhopadhyay S, Mahajan P, Chalk R, et al. Structure of the polycystic kidney disease TRP channel Polycystin-2 (PC2). Nat Struct Mol Biol. 2017;24(2):114-22. https://doi.org/10.1038/nsmb.3343.

3. Chumley P, Zhou J, Mrug S, Chacko B, Parant JM, Challa AK, Wilson LS, Berryhill TF, Barnes S, Kesterson RA, et al. Truncating PKHD1 and PKD2 mutations alter energy metabolism. Am J Physiol Renal Physiol. 2019;316(3):F414-25. https://doi.org/10.1152/ajprenal.00167.2018.

4. Kim DY, Park JH. Genetic mechanisms of ADPKD. Adv Exp Med Biol. 2016;933:13-22. https://doi.org/10.1007/978-981-10-2041-4_2.

5. Cornec-Le GE, Olson RJ, Besse W, Heyer CM, Gainullin VG, Smith JM, Audrezet MP, Hopp K, Porath B, Shi B, et al. Monoallelic mutations to DNAJB11 cause atypical autosomal-dominant polycystic kidney disease. Am J Hum Genet. 2018;102(5):832-44. https://doi.org/10.1016/j.ajhg. 2018.03.013. 
6. Padovano V, Podrini C, Boletta A, Caplan MJ. Metabolism and mitochondria in polycystic kidney disease research and therapy. Nat Rev Nephrol. 2018;14(11):678-87. https://doi.org/10.1038/s41581-018-0051-1.

7. Bergmann C. Recent advances in the molecular diagnosis of polycystic kidney disease. Expert Rev Mol Diagn. 2017;17(12):1037-54. https://doi. org/10.1080/14737159.2017.1386099.

8. Yang Y, Muzny DM, Xia F, Niu Z, Person R, Ding Y, Ward P, Braxton A, Wang $M$, Buhay $C$, et al. Molecular findings among patients referred for clinical whole-exome sequencing. JAMA. 2014;312(18):1870-9. https://doi.org/ 10.1001/jama.2014.14601.

9. Mallawaarachchi AC, Hort Y, Cowley MJ, McCabe MJ, Minoche A, Dinger ME, Shine J, Furlong TJ. Whole-genome sequencing overcomes pseudogene homology to diagnose autosomal dominant polycystic kidney disease. Eur J Hum Genet. 2016;24(11):1584-90. https://doi.org/10.1038/ ejhg.2016.48.

10. Braun DA, Schueler M, Halbritter J, Gee HY, Porath JD, Lawson JA, Airik R, Shril S, Allen SJ, Stein D, et al. Whole exome sequencing identifies causative mutations in the majority of consanguineous or familial cases with childhood-onset increased renal echogenicity. Kidney Int. 2016:89(2):468-75. https://doi.org/10.1038/ki.2015.317.

11. Chen S, Zhou Y, Chen Y, Gu J. fastp: an ultra-fast all-in-one FASTQ preprocessor. Bioinformatics. 2018;34(17):i884-90. https://doi.org/10.1093/bioin formatics/bty560.

12. Kumar P, Henikoff S, Ng PC. Predicting the effects of coding non-synonymous variants on protein function using the SIFT algorithm. Nat Protoc. 2009;4(7):1073-81. https://doi.org/10.1038/nprot.2009.86.

13. Flanagan SE, Patch AM, Ellard S. Using SIFT and PolyPhen to predict lossof-function and gain-of-function mutations. Genet Test Mol Biomarkers. 2010;14(4):533-7. https://doi.org/10.1089/gtmb.2010.0036

14. Schwarz JM, Rodelsperger C, Schuelke M, Seelow D. MutationTaster evaluates disease-causing potential of sequence alterations. Nat Methods. 2010;7(8):575-6. https://doi.org/10.1038/nmeth0810-575.

15. Itan Y, Shang L, Boisson B, Ciancanelli MJ, Markle JG, Martinez-Barricarte R, Scott E, Shah I, Stenson PD, Gleeson J, et al. The mutation significance cutoff: gene-level thresholds for variant predictions. Nat Methods. 2016;13(2):109-10. https://doi.org/10.1038/nmeth.3739.

16. Liu X, Wu C, Li C, Boerwinkle E. dbNSFP v3.0: a one-stop database of functional predictions and annotations for human nonsynonymous and splice-site SNVs. Hum Mutat. 2016;37(3):235-41. https://doi.org/10.1002/ humu.22932.

17. Yu G, Wang LG, Han Y, He QY. clusterProfiler: an R package for comparing biological themes among gene clusters. OMICS. 2012;16(5):284-7. https://doi.org/10.1089/omi.2011.0118.

18. Song X, Di Giovanni V, He N, Wang K, Ingram A, Rosenblum ND, Pei Y. Systems biology of autosomal dominant polycystic kidney disease (ADPKD): computational identification of gene expression pathways and integrated regulatory networks. Hum Mol Genet. 2009;18(13):2328-43. https://doi.org/10.1093/hmg/ddp165.

19. Law CW, Alhamdoosh M, Su S, Dong X, Tian L, Smyth GK, Ritchie ME. RNAseq analysis is easy as 1-2-3 with limma, Glimma and edgeR. F1000Res. 2016. https://doi.org/10.12688/f1000research.9005.3.

20. Cornec-Le Gall E, Alam A, Perrone RD. Autosomal dominant polycystic kidney disease. Lancet. 2019;393(10174):919-35. https://doi.org/10.1016/ S0140-6736(18)32782-X.
21. Douguet D, Patel A, Honore E. Structure and function of polycystins: insights into polycystic kidney disease. Nat Rev Nephrol. 2019;15(7):41222. https://doi.org/10.1038/s41581-019-0143-6.

22. Ghata J, Cowley BD Jr. Polycystic kidney disease. Compr Physiol. 2017;7(3):945-75. https://doi.org/10.1002/cphy.c160018.

23. Shi W, Xu D, Gu J, Xue C, Yang B, Fu L, Song S, Liu D, Zhou W, Lv J, et al. Saikosaponin-d inhibits proliferation by up-regulating autophagy via the CaMKKbeta-AMPK-mTOR pathway in ADPKD cells. Mol Cell Biochem. 2018:449(1-2):219-26. https://doi.org/10.1007/s11010-018-3358-0.

24. Sun Y, Liu Z, Cao X, Lu Y, Mi Z, He C, Liu J, Zheng Z, Li MJ, Li T, et al. Activation of P-TEFb by CAMP-PKA signaling in autosomal dominant polycystic kidney disease. Sci Adv. 2019;5(6):eaaw3593. https://doi.org/10.1126/ sciadv.aaw3593.

25. Kang HW, Ozdemir C, Kawano Y, LeClair KB, Vernochet C, Kahn CR, Hagen SJ, Cohen DE. Thioesterase superfamily member 2/Acyl-CoA thioesterase 13 (Them2/Acot13) regulates adaptive thermogenesis in mice. J Biol Chem. 2013;288(46):33376-86. https://doi.org/10.1074/jbc.M113.481408.

26. Lin CC, Kurashige M, Liu Y, Terabayashi T, Ishimoto Y, Wang T, Choudhary $\checkmark$, Hobbs R, Liu LK, Lee PH, et al. A cleavage product of Polycystin-1 is a mitochondrial matrix protein that affects mitochondria morphology and function when heterologously expressed. Sci Rep. 2018;8(1):2743. https:// doi.org/10.1038/s41598-018-20856-6.

27. Tian L, Suzuki M, Nakajima T, Kubo R, Sekine Y, Shibuya K, Hiroshima K, Nakatani Y, Fujisawa T, Yoshino I, et al. Clinical significance of aberrant methylation of prostaglandin E receptor 2 (PTGER2) in nonsmall cell lung cancer: association with prognosis, PTGER2 expression, and epidermal growth factor receptor mutation. Cancer. 2008;113(6):1396-403. https:// doi.org/10.1002/cncr.23694.

28. Baba Y, Nosho K, Shima K, Goessling W, Chan AT, Ng K, Chan JA, Giovannucci EL, Fuchs CS, Ogino S. PTGER2 overexpression in colorectal cancer is associated with microsatellite instability, independent of CpG island methylator phenotype. Cancer Epidemiol Biomarkers Prev. 2010;19(3):822-31. https://doi.org/10.1158/1055-9965.EPI-09-1154.

29. Sugino Y, Misawa A, Inoue J, Kitagawa M, Hosoi H, Sugimoto T, Imoto I, Inazawa J. Epigenetic silencing of prostaglandin E receptor 2 (PTGER2) is associated with progression of neuroblastomas. Oncogene. 2007;26(53):7401-13. https://doi.org/10.1038/sj.onc.1210550.

30. Liu Y, Rajagopal M, Lee K, Battini L, Flores D, Gusella GL, Pao AC, Rohatgi R. Prostaglandin E(2) mediates proliferation and chloride secretion in ADPKD cystic renal epithelia. Am J Physiol Renal Physiol. 2012;303(10):F1425-1434. https://doi.org/10.1152/ajprenal.00010.2012.

31. Elberg G, Elberg D, Lewis TV, Guruswamy S, Chen L, Logan CJ, Chan MD, Turman MA. EP2 receptor mediates PGE2-induced cystogenesis of human renal epithelial cells. Am J Physiol Renal Physiol. 2007;293(5):F1622-1632. https://doi.org/10.1152/ajprenal.00036.2007.

\section{Publisher's Note}

Springer Nature remains neutral with regard to jurisdictional claims in published maps and institutional affiliations.

\footnotetext{
Ready to submit your research? Choose BMC and benefit from:

- fast, convenient online submission

- thorough peer review by experienced researchers in your field

- rapid publication on acceptance

- support for research data, including large and complex data types

- gold Open Access which fosters wider collaboration and increased citations

- maximum visibility for your research: over $100 \mathrm{M}$ website views per year
}

At BMC, research is always in progress.

Learn more biomedcentral.com/submissions 